\title{
Subakut tiroidit tanılı hastaların demografik özellikleri ve laboratuvar verilerinin analizi: tek merkez deneyimi
}

\section{Demographic characteristics of patients with subacute thyroiditis and analysis of laboratory data: single center experience}

\author{
Yakup Ergün ${ }^{1} \quad$ Alpaslan Kemal Tuzcu ${ }^{2}$ \\ ${ }^{1}$ Ankara Numune Eğitim ve Araştırma Hastanesi, Tıbbi Onkoloji Bölümü, Ankara, Türkiye \\ ${ }^{2}$ Dicle Üniversitesi Tıp Fakültesi, Endokrinoloji Bilim Dalı, Diyarbakır, Türkiye
}

Öz

Amaç: Tiroid bezinin inflamatuvar bir hastalığı olan subakut tiroidit tirotoksikozların nadir bir nedenidir. Çalışmamızda endokrinoloji polikliniğimize başvurup subakut tiroidit tanısı alan hastaları retrospektif olarak inceleyip bu hastalarda tanı koymada yeni ipuçlarını araştırmayı amaçladık.

Gereç ve Yöntem: 2010-2014 yılları arasında polikliniğimize başvurup subakut tiroidit tanısı alan 50 hasta ile tiroid bezi ile ilgili herhangi bir patolojisi olmayan, kontrol amaçlı polikliniğe başvuran 50 sağlıklı kişi olmak üzere toplam 100 kişi çalışmaya dahil edildi. Hasta verileri retrospektif olarak incelendi.

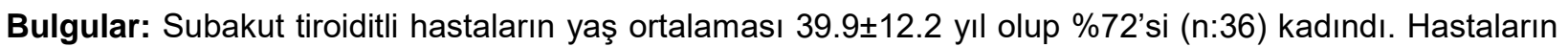
\%42'si sonbahar, \%26'sı ilkbahar, \%20'si yaz ve \%12'si kış mevsiminde tanı almışlardı. Sedimantasyon hızı ve CRP hasta grubunda anlamlı olarak yüksek bulundu (sırasıyla; $53.7 \pm 14.22 \mathrm{~mm} / \mathrm{saat}$, $7.07 \pm 5.64$ $\mathrm{mg} / \mathrm{dl}, \mathrm{p}<0.01$ ). Lökosit sayısı, nötrofil sayısı, nötrofil/lenfosit oranı ve T4/T3 oranı hasta grupta anlamlı olarak yüksek bulunurken lenfosit sayısı arasında anlamlı fark saptanmadı. Ortalama trombosit hacmi (MPV) kontrol grubuna kıyasla hasta grupta anlamlı olarak düşük saptandı $(p<0.01)$. Tiroid otoantikorları açısından yapılan değerlendirmede anti tiroglobulin (Anti $\mathrm{Tg}$ ) pozitifliği hasta grupta anlamlı olarak yüksek bulundu (sırasıyla; \%46.5 ve \%12). Anti tiroid peroksidaz (Anti TPO) pozitifliği açısından anlamlı fark bulunmadı.

Sonuç: Subakut tiroidit tanılı hastalarda Anti Tg düzeylerinin yüksek olabileceği gözlenmiş olup, Anti $\mathrm{Tg}$ pozitif hastalarda subakut tiroidit tanısı dışlanmamalıdır. Subakut tiroiditli hastalarda T4/T3 oranı ve nötrofil/lenfosit oranının artmış olduğunu, MPV düzeyinin ise düşük olduğunu saptadık. Bu parametrelerin subakut tiroidit ile diğer tirotoksikoz/hipertiroidi nedenleri arasında ayırıcı tanıda kullanılması için başka çalışmalarla desteklenmesi gerekmektedir.

Anahtar Sözcükler: subakut tiroidit, mevsimsel ilişki, sedimantasyon, anti tiroglobulin, MPV.
Abstract diagnosis of these patients.

\footnotetext{
Yazışma Adresi: Yakup Ergün

Ankara Numune Eğitim ve Araştırma Hastanesi, Tıbbi Onkoloji

Bölümü, Ankara, Türkiye

E-mail: dr.yakupergun@gmail.com

Makalenin Geliş Tarihi: 29.07.2018

Kabul Tarihi: 29.08.2018
}

Aim: In this study, we aimed to investigate retrospectively the patients diagnosed with subacute thyroiditis who were admitted to our endocrinology outpatient clinic and to search for new clues in

Materials and Methods: Fifty patients with subacute thyroiditis and 50 patients without any thyroid disease were included in the study. Patient data were analyzed retrospectively. 
Results: The mean age of the patients with subacute thyroiditis was $39.9 \pm 12.2$ years and $72 \%$ (n:36) were female. Subacute thyroiditis was diagnosed in $42 \%$ of the patients in autumn, $26 \%$ in spring, $20 \%$ in summer and $12 \%$ in winter. Sedimentation rate and CRP were significantly higher in the patient group $(53.7 \pm 14.22 \mathrm{~mm} / \mathrm{h}, 7.07 \pm 5.64 \mathrm{mg} / \mathrm{dl}$, respectively, $p<0.01)$. Leukocyte count, neutrophil count, neutrophil/lymphocyte ratio and T4/T3 ratio were significantly higher in the patient group. Mean platelet volume (MPV) were significantly lower in the patient group compared to the control group $(p<0.01)$. In the evaluation of thyroid autoantibodies, anti-thyroglobulin (Anti $\mathrm{Tg}$ ) positivity was significantly higher in the patient group $(46.5 \%$ and $12 \%$, respectively). There was no significant difference in anti-thyroid peroxidase (Anti TPO) positivity.

Conclusion: Anti Tg levels may be elevated in patients with subacute thyroiditis. Subacute thyroiditis should not be excluded in anti Tg positive patients. We found that T4/T3 ratio and neutrophil/lymphocyte ratio were increased and MPV level was low in patients with subacute thyroiditis. In order to use these parameters in the differential diagnosis between subacute thyroiditis and other causes of thyrotoxicosis/hyperthyroidism, should be supported by further studies.

Keywords: subacute thyroiditis, seasonal association, sedimentation, anti-thyroglobulin, MPV.

\section{Giriş}

Tiroid bezinin inflamatuvar bir hastalığı olan subakut tiroidit için "subakut nonsüpüratif tiroidit, subakut granülomatöz tiroidit, dev hücreli tiroidit, ağrılı tiroidit ve De Quervan tiroiditi" gibi farklı tanımlamalar mevcuttur. Hipertiroidinin / tirotoksikozun nadir bir nedeni olan bu hastalıkta kadın/erkek oranı 3-5/1'dir (1). Subakut tiroidit, boyun ağrısı ve/veya hassasiyet, tiroid fonksiyonlarında dönemsel değişimler ile karakterizedir. Hastalığın etiyolojisi kesin olarak bilinmemekle birlikte, viral bir hastalık olduğu yönünde kuvvetli bulgular mevcut (2). Hastalığın klasik doğal seyri tirotoksikoz-ötiroidihipotiroidi ve ardından ötiroididir. Bu dönemler hastaların ancak \%40'ı tarafından yaşanmaktadır. $\% 60$ 'ı oluşturan daha hafif olgularda, tirotoksik dönemi takiben hipotiroidi gelişmez, hastalar ötiroid kalırlar. Ancak \%5 vakada kalıcı hipotiroidi gelişmektedir (3). Aktif evrede eritrosit sedimantasyon hızı $(E S H)$ ve $C$ reaktif protein (CRP) yüksekliği en önemli ipucudur (4). Sedimantasyon yüksekliği ile birlikte artmış serum serbest T4 (sT4), serbest T3 (sT3), azalmış RAIU (radyoaktif iyot uptake) tanı için en tipik kombinasyondur (5). Semptomları hafif seyreden vakalarda tedaviye intiyaç olmayabilir. Diğer vakalarda nonsteroid antiinflamatuvar ajanlar kullanılabilir ancak çoğu vaka kortikosteroidlere intiyaç duymaktadır. Kortikosteroidler ile tedaviye yanıt dramatiktir ve kısa süreli düşük doz steroidin yan etkileri çoğu vaka için ihmal edilebilecek kadar düşüktür (6).

Amacımız; hastanemiz endokrinoloji polikliniğine başvurup subakut tiroidit tanısı alan hastaların demografik özelliklerini ve laboratuvar verilerini inceleyip, ayırıcı tanıda kullanılabilecek parametre tespiti ve erken tanıda hangi özelliklerin dikkate alınması gerektiğini araştırmaktır.

\section{Gereç ve Yöntem}

\section{Hasta özellikleri}

2010-2014 yılları arasında Dicle Üniversitesi Tıp Fakültesi Endokrinoloji polikliniğine başvuran ve subakut tiroidit tanısı almış olan 50 hasta ile tiroid bezi ile ilgili herhangi bir patolojisi olmadığı tespit edilen kontrol amaçlı polikliniğe başvuran 50 sağlıklı kişi olmak üzere toplam 100 kişi çalışmaya dahil edildi. Çalışmaya alınan hasta ve sağlıklı gönüllülerin verileri retrospektif olarak değerlendirildi. Bu çalışma için üniversitemizin medikal araştırma etik kuruluna yazılı başvuru yapılarak onay alınmıştır (Proje Numarası: 08, Onay tarihi: 26/12/2014).

Çalışmaya alınan hasta ve sağlıklı gönüllülerin dosyalarından; tanı yaşı, cinsiyet, geldiği şehir, tanı ayı ve yılı, şikayetleri, ek hastalıkların varlığı, tanı anındaki ve kontrollerdeki serum sT4, sT3, tiroid stimülan hormon (TSH), tiroid otoantikorları (antiTPO ve anti-Tg), tiroglobulin ( $\mathrm{Tg}$ ), sedimantasyon, CRP, hemogram, alanin aminotransferaz (ALT), aspartat aminotransferaz (AST), hemogram parametreleri, ferritin seviyeleri ile tiroid ultrasonografi ve tiroid sintigrafi bulguları tarandı.

Subakut tiroidit tanısı anamnez, klinik ve laboratuvar/görüntüleme bulguları ile konmuştur. Çalışmaya alınan hastaların tümünün tiroid sintigrafi sonucunun süprese olmasına dikkat edildi. Süprese olmayan vakalar çalışma dışı bırakıldı. 


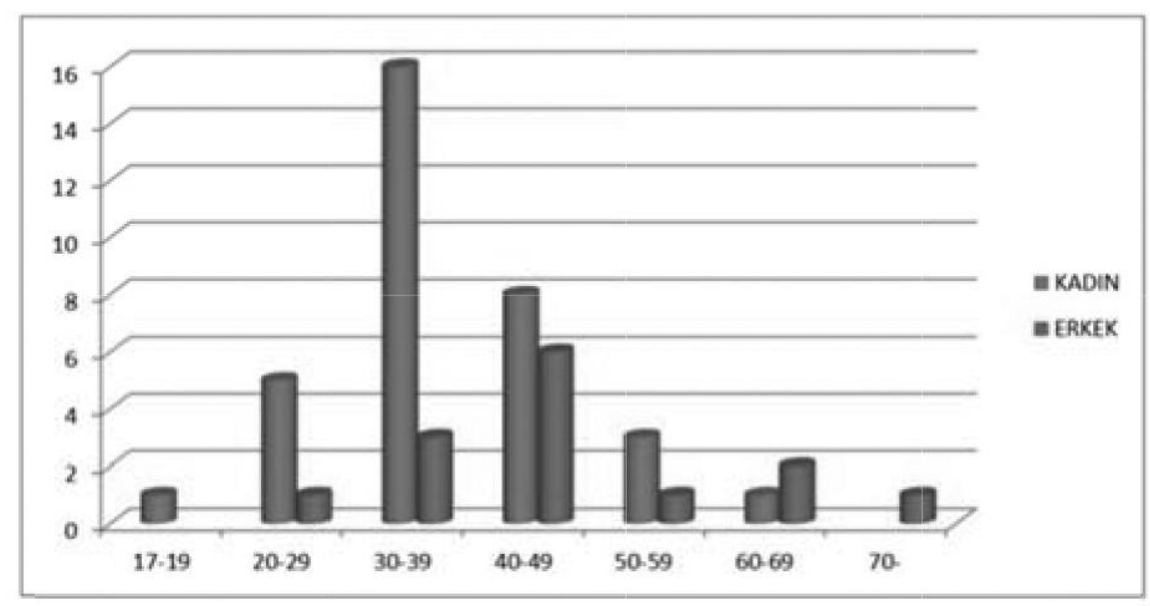

Şekil-1. Cinsiyete göre yaş dağılımı.

\section{Istatistiksel analiz}

Çalışmada elde edilen bulgular değerlendirilirken istatistiksel analizler için SPSS 18.0 bilgisayar programı kullanıldı. Ölçümsel değişkenler ortalama \pm standart sapma ile, kategorik değişkenler sayı ve yüzde (\%) ile sunuldu. İki grup arasındaki özelliklerin farklılıkları pearson ki-kare testi ile analiz edildi, $p<0.05$ istatistiksel olarak anlamlı kabul edildi.

\section{Bulgular}

\section{Demografik Bulgular}

Subakut tiroidit tanılı hastaların ve kontrol grubundaki sağlıklı kişilerin 36'sı (\%72) kadın, 14'ü (\%28) erkekti (K/E: 2.6:1). Subakut tiroiditli hastaların yaş ortalaması $39.9 \pm 12.2 \mathrm{yıl}$, kontrol grubunun yaş ortalaması $37.8 \pm 13.6 \mathrm{yıl}$ idi. İki grup arasında yaş ve cinsiyet açısından fark bulunmadı $(p>0.05)$. Subakut tiroiditli kadın hastaların yaş ortalaması $37.6 \pm 10.2 \mathrm{yıl}$, erkek hastaların yaş ortalaması 46.1 \pm 15 yıl idi (Şekil-1).

Hastalığın mevsimsel ilişkisi açısından yapılan değerlendirmede olguların \%42'si sonbahar, \%26'sı ilkbahar, \%20'si yaz ve \%12'sine kış mevsiminde tanı konduğu tespit edildi (Şekil-2).

\section{Laboratuar Bulguları}

Sedimantasyon hızı ve CRP hasta grubunda anlamlı olarak yüksek bulundu $(53.7 \pm 14.22$ $\mathrm{mm} / \mathrm{saat}, \quad 7.07 \pm 5.64 \mathrm{mg} / \mathrm{dl}$ sirasıyla, $\mathrm{p}<0.01$ ). Hastalarımızın \%86'sında ESH 40 mm/saat'in üstünde, $\% 60$ 'ında $50 \mathrm{~mm} / \mathrm{saat}$ 'in üstünde, $\% 26$ 'sında $60 \mathrm{~mm} / \mathrm{saat}$ 'in üstünde bulduk. Lökosit sayısı, nötrofil sayısı, nötrofil yüzdesi, lenfosit yüzdesi, nötrofil lenfosit oranı (NLO) ve trombosit sayısı hasta grubunda anlamlı olarak yüksek bulunurken lenfosit sayısı açısından fark saptanmadı.

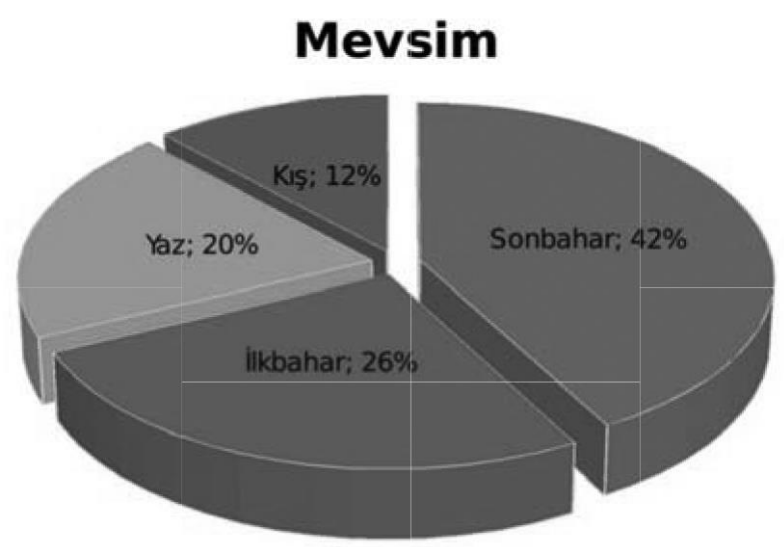

Şekil-2. Mevsimlere göre dağılım.

Hemoglobin ve hematokrit değerleri hasta grubunda anlamlı olarak düşük saptandı. Ortalama trombosit hacmi (OTH, MPV) ve trombosit dağılım genişliği (TDG, PDW) kontrol grubuna kıyasla hasta grubunda anlamlı olarak düşük saptandı $(p<0.01)$. ALT seviyesi hasta grubunda anlamlı olarak yüksek bulunurken, AST açısından fark saptanmadı. ST3, sT4 ve sT4/sT3 oranı hasta grubunda anlamlı olarak yüksek bulunurken TSH 
düşük bulundu $(p<0.01)$ (Tablo-1). Hasta grubunda 14 hastada ferritin çalışılmış olup 12'sinde (\%85.7) üst sınırdan yüksek çıktı, ortalama ferritin $389.2 \pm 313 \mathrm{ng} / \mathrm{mL}$ olarak bulundu.

Tiroid otoantikorları açısından yapılan değerlendirmede anti tiroglobulin (Anti-Tg) pozitifliği hasta grubunda anlamlı olarak yüksek bulundu (\%46.5, \%12 sirasıyla). Anti tiroid peroksidaz pozitifliği açısından fark saptanmadı. Hasta grubunda 11 hastadan tiroglobulin $(\mathrm{Tg})$ çalışıımış olup \%72.7 sinde pozitifti (Tablo-2).

Tablo-1. Laboratuvar bulguları.

\begin{tabular}{|c|c|c|c|}
\hline $\begin{array}{c}\text { Parametre } \\
\text { (Normal aralık) }\end{array}$ & $\begin{array}{c}\text { Hasta grubu }(\mathrm{n}=50) \\
\text { (Ortalama) }\end{array}$ & $\begin{array}{c}\text { Kontrol grubu }(\mathrm{n}=50) \\
\text { (Ortalama) }\end{array}$ & p-değeri \\
\hline Sedimantasyon & $53.7 \pm 14.22$ & $11 \pm 6.9$ & 0.001 \\
\hline 8-15 mm/saat) & $\mathrm{n}=50$ & $\mathrm{n}=50$ & \\
\hline CRP & $7.07 \pm 5.64$ & $0.45 \pm 0.37$ & 0.001 \\
\hline$(0-0.8 \mathrm{mg} / \mathrm{dl})$ & $n=50$ & $n=50$ & \\
\hline Lökosit & $9.94 \pm 3.49$ & $7.86 \pm 1.8$ & 0.002 \\
\hline$(4.6-10.2 \mathrm{~K} / \mu \mathrm{l})$ & $\mathrm{n}=49$ & $n=50$ & \\
\hline Nötrofil \% & $66.9 \pm 9.59$ & $58.5 \pm 9.1$ & 0.001 \\
\hline$(37-80 \%)$ & $n=49$ & $\mathrm{n}=50$ & \\
\hline Lenfosit \% & $23.64 \pm 8.29$ & $31 \pm 8.17$ & 0.001 \\
\hline$(10-50 \%)$ & $n=49$ & $n=50$ & \\
\hline \multirow[t]{2}{*}{ Nötrofil Lenfosit oranı (NLO) } & $3.56 \pm 2.64$ & $2.15 \pm 1.1$ & 0.001 \\
\hline & $n=49$ & $\mathrm{n}=50$ & \\
\hline Hemoglobin & $12.12 \pm 1.46$ & $13.83 \pm 1.59$ & 0.001 \\
\hline$(12.2-18.1 \mathrm{~g} / \mathrm{dl})$ & $\mathrm{n}=49$ & $n=50$ & \\
\hline Trombosit & $367.63 \pm 117.14$ & $283.3 \pm 82$ & 0.001 \\
\hline$(142-424 \mathrm{~K} / \mu \mathrm{l})$ & $n=49$ & $\mathrm{n}=50$ & \\
\hline MPV & $7.81 \pm 1.1$ & $8.8 \pm 1.36$ & 0.001 \\
\hline$(0.00-99.9 \mathrm{fL})$ & $n=49$ & $n=50$ & \\
\hline PDW & $17.77 \pm 1.19$ & $20.2 \pm 1.1$ & 0.001 \\
\hline$(0.00-99.9)$ & $n=49$ & $n=50$ & \\
\hline sT3 & $11.03 \pm 5.45$ & $4.83 \pm 0.49$ & 0.001 \\
\hline (3.9-6.7 pmol/L) & $n=50$ & $n=50$ & \\
\hline sT4 & $42.18 \pm 17.67$ & $16.64 \pm 2.52$ & 0.001 \\
\hline (12-22 pmol/L) & $n=50$ & $n=50$ & \\
\hline \multirow[t]{2}{*}{ sT4 sT3 oranı } & $4.1 \pm 1.32$ & $3.4 \pm 0.6$ & 0.001 \\
\hline & $n=50$ & $\mathrm{n}=50$ & \\
\hline TSH & $0.03 \pm 0.05$ & $1.6 \pm 1.25$ & 0.001 \\
\hline (0.27-4.2 mlU/mL) & $n=50$ & $n=50$ & \\
\hline ANTi-Tg & $216.46 \pm 264.09$ & $60.6 \pm 115.7$ & 0.001 \\
\hline (0-115 IU/mL) & $n=43$ & $\mathrm{n}=50$ & \\
\hline ANTI-TPO & $19.3 \pm 48.49$ & $17.8 \pm 23.4$ & 0.2 \\
\hline (0-35 IU/mL) & $n=36$ & $\mathrm{n}=50$ & \\
\hline ALT & $39.9 \pm 56.93$ & $20.33 \pm 10.06$ & 0.02 \\
\hline$(10-35 \mathrm{U} / \mathrm{L})$ & $n=50$ & $n=50$ & \\
\hline AST & $25.89 \pm 24.55$ & $18.89 \pm 5.02$ & 0.06 \\
\hline (10-40 U/L) & $\mathrm{n}=50$ & $n=50$ & \\
\hline
\end{tabular}


Tablo-2. Tiroid otoantikoru pozitiflik bulguları.

\begin{tabular}{llll} 
& \multicolumn{1}{c}{$\begin{array}{c}\text { Hasta grubu } \\
(\mathbf{n}=50)\end{array}$} & \multicolumn{1}{c}{$\begin{array}{c}\text { Kontrol grubu } \\
(\mathbf{n}=\mathbf{5 0})\end{array}$} & p-değeri \\
\hline Anti-Tg & $\% 46.5(\mathrm{n}=43)$ & $\% 12(\mathrm{n}=50)$ & 0.001 \\
Anti-TPO & $\% 5.6(\mathrm{n}=36)$ & $\% 10(\mathrm{n}=50)$ & 0.46 \\
\hline
\end{tabular}

Tablo-3. Ultrasonografi bulguları.

\begin{tabular}{lll}
\hline Bulgular & & $\mathbf{n}(\%)$ \\
\hline Nodul & & 31 \\
& Var & $14(\% 45,1)$ \\
Parankim & Yok & $17(\% 54,9)$ \\
& & 31 \\
& Heterojen & $28(\% 90,3)$ \\
Heterojenite & Homojen & $3(\% 9,7)$ \\
& Diffüz & 28 \\
Volüm & Fokal & $22(\% 78,5)$ \\
& & $6(\% 21,5)$ \\
& Normal & 31 \\
Lenfadenomegali & $21(\% 67,7)$ \\
& Artmış & $10(\% 32,3)$ \\
& Var & 17 \\
\hline
\end{tabular}

12 aydan daha uzun süre takip edilen 18 hastanın 2'sinde (\%11.1) kalıcı hipotiroidi gelişmiş olup sürekli tiroid replasman tedavisi uygulanmıştır.

Hastaların tiroid ultrasonografi bulguları Tablo-3'te sunulmuştur.

\section{Tartışma}

Tiroid bezinin inflamatuar bir hastalığı olan subakut tiroidit en sık 30-50 yaş aralığında görülmektedir (7). Erdem ve ark. (8) ortalama tanı yaşını 34 \pm 17.8 yıl, Assim ve ark. (9) $35 \pm 11.2$ yıl, Cappelli ve ark. (10) $45.4 \pm 9.7$ yıl olarak bildirilmişlerdir. Bizim çalışmamızda vakaların ortalama yaşı $39.9 \pm 12.2$ yıl olup literatür ile uyumlu bulundu. Çalışma sonucumuza göre subakut tiroidit 3 . ve 4 . dekatların hastalığı olduğu söylenebilir.

Subakut tiroidit, kadınlarda 3-5 kat artmış sıklıkta izlenmekte olup (1), yapılan pek çok çalışmada 1.8-14.1 arasında değişen oranlar bildirilmiştir (710). 38 yıl takip süreli bir Minnesota çalışmasında 1960-1998 yılları arasında 94 subakut tiroiditli hasta tespit edilmiş olup 1960'lar, 1970'ler, 1980 'ler ve 1990 'larda sırasıyla kadın erkek oranı 14.1/1, 9/1, 4.7/1, 4.6/1 olarak bildirilmiştir (7).
Bizim çalışmamızda kadın/erkek oranı 2.6/1 idi ve kadın dominansı literatür ile uyumlu bulundu.

Mevsimsel ilişki açısından yapılan çalışmalarda, Fatourechi ve ark. (7) 38 yıllık çalışmasında da sıklık sırasına göre ilkbahar (\%28.7), sonbahar (\%28.1), yaz (\%22.5), kış (\%21.8), Martino ve ark. (11) yaz aylarında daha sık görüldüğünü bildirmişlerdir. Bizim çalışmamızda da mevsimsel ilişki saptanmış olup bahar aylarında daha sık görülmektedir. Aylara göre incelendiğinde ağustos ve eylül aylarında vaka sayılarındaki artış mevsimsel geçişlerde özellikle yazdan sonbahara geçişte hastalık sıklığının arttığını göstermektedir. Mevsimsel ilişki nedeninin üst solunum yolu enfeksiyonlarının sonbaharda artan insidansı olarak değerlendirilebilir.

ESH ve CRP akut faz yanıtını değerlendirmede sık kullanılan testlerdendir. $\mathrm{Bu}$ testler pek çok durumda yükselebildiğinden, tek bir hastalığa özgül olmadığından tanı amaçlı kullanılmayıp, klinik şüpheleri destekleyici veya tanısı konulmuş çeşitli hastalıkların seyrini takip için kullanılır. Subakut tiroiditle ilgili yapılan çalışmalarda, Fatourechi ve ark. (7) ortalama ESH $51 \pm 26$ 
$\mathrm{mm} / \mathrm{saat}$, Erdem ve ark. (8) 43.42 \pm 39.6 , Uysal ve ark. (12) $84.7 \mathrm{~mm} / \mathrm{saat}$ olarak bildirmişlerdir. Biz de çalışmamızda literatür ile uyumlu olarak ortalama ESH'yi $53.7 \pm 14.2 \mathrm{~mm} / \mathrm{saat}$, ortalama CRP'yi $7.07 \pm 5.64 \mathrm{mg} / \mathrm{dl}$ olarak bulduk. Hastalığın ilerleyen dönemlerinde inflamasyonun gerilemesine paralel olarak $E S H$ ve CRP değerlerinde düşme olağandır ancak tirotoksik faz olan aktif dönemde normal değerler tanıya şüpheli yaklaşmayı gerektirir.

İnflamatuar durumlarda salgılanan çeşitli sitokinler kan hücreleri üzerinde nicelik ve niteliksel olarak bir takım değişikliklere sebep olmaktadır. Bu değişiklikler subakut tiroiditli hastalarda da gözlenmektedir. Viral enfeksiyonların seyri sırasında ön planda lenfositoz beklenir. Subakut tiroidit etiyolojisinde de viral ajanlar suçlandığından lenfositoz olması beklenebilir. Ancak çalışma sonuçlarımız nötrofil hakimiyetinin daha ön planda olduğunu göstermektedir. Bu durum etiyolojide bakteriyel ajanların veya farklı etmenlerin de rol oynayabileceğini düşündürmektedir. NLO son yıllarda subklinik inflamasyonu göstermede önem kazanmış ucuz ve elde edilebilirliği kolay bir testtir. Bizim çalışmamızda da NLO hasta grubunda kontrol grubuna göre anlamlı olarak yüksek bulundu, ancak NLO tiroid hastalıkları ile ilişkisine yönelik yeterli çalışma olmadığından bu parametrenin klinik kullanıma girmesi için geniş kapsamlı çalışmalara intiyaç vardır.

Subakut tiroidit ve trombosit fonksiyonu arasındaki ilişki çalışmamızda özellikle incelenmiştir. MPV, eritrositler için kullanılan MCV'ye benzer şekilde trombositlerin dolaşımdaki ortalama büyüklüğünü yansıtır (13). Pek çok hormon ve immün sistemde rol alan mediyatör, trombopoetik hücrelerin olgunlaşması ve trombositlerin dolaşıma salınımında etkiye sahiptir. Çeşitli fizyolojik ve patolojik durumlarda, aktif trombosit intiyacına göre megakaryositopoez yeniden düzenlenmekte ve trombosit indekslerinde zaman bağımlı değişikliklere neden olmaktadır (14). Ancak bu değişikliklerin her zaman doğrusal bir şekilde olmaması, karmaşık immün ve inflamatuvar mekanizmalardan etkilendiğini düşündürmektedir. MPV ile tiroid hastalıkları arasında çok az sayıda çalışma mevcuttur. MPV ile tiroid hastalıkları arasındaki ilişkiyi araştıran ilk çalışmalardan biri olan Ford ve ark. (15) yirmi sekiz vakalık alt tipi belirlenmemiş tirotoksikoz serisinde MPV'yi artmış olarak bulmuşlardı. Lippi ve ark. (16) TSH ile MPV arasında pozitif korelasyon bulmuşken, Ren ve ark. (17) ise herhangi bir ilişki saptamamışlar. Bizim çalışmamızda hasta grubu ile kontrol grubu karşılaştırıldığında trombosit sayısı hasta grubunda anlamlı olarak daha yüksek, MPV ise anlamlı olarak düşük bulundu. Ford $\mathrm{HC}$ ve arkadaşlarının alt tipi belirlenmemiş tirotoksikoz hastalarında MPV'yi yüksek bulması, bizim çalışmamızda ise tirotoksikozun bir nedeni olan subakut tiroidit hastalarında MPV'yi düşük bulmamız tirotoksikoz ayırıcı tanısında MPV'nin kullanılabileceğini düşündürmektedir. Tiroid hastalıkları (özellikle hipertiroidi alt tipleri) ve MPV arasındaki ilişkiyi gösteren çalışma sayısının artması ile MPV'nin tanıda önemli bir yer edineceğini düşünüyoruz.

Subakut tiroiditin ilk aşamasında tiroid hücre harabiyeti nedeniyle tiroid hormon düzeyleri artar. Tirotoksikoza bağlı olarak negatif feed-back ile TSH baskılanır. Bizim bulgularımız da literatür ile uyumluydu. Bir diğer hormonal parametre sT4/sT3'tür. Mortoglou ve ark. (18) 236 hipertiroidi (Graves hastalığı, toksik multinodüler guatr) hastası ile 69 subakut tiroiditli hasta içeren çalışmalarında sT3, sT4 ve TSH düzeyleri arasında anlamlı fark bulmazken, subakut tiroiditli hastalarda sT4/sT3 oranını anlamlı olarak daha yüksek bulmuşlardır. Bizim çalışmamızda hasta grubunda sT4/sT3 oranını $4.1 \pm 1.32$ kontrol grubunda ise $3.43 \pm 0.57$ olarak bulduk ve aralarındaki fark istatiksel olarak anlamlıydı $(p<0.01)$. Subakut tiroiditte sT4'ün daha fazla artması tiroid hormon sentezinden ziyade tiroid folikül harabiyetinden dolayı kana salınan hormonlardan kaynaklandığı muhtemeldir. sT4/sT3 oranının tiroid hastalıklarının ayrıcı tanısında kullanılabilmesi için daha fazla çalışmaya intiyaç vardır.

Tiroid otoantikorları subakut tiroiditte genellikle negatif veya düşük titrede pozitif beklenir (19). Ancak yapılan çalışmalar bu durumun net olmadığını göstermektedir. Erdem ve arkadaşlarının (8) yaptıkları çalışmada anti tiroglobulini (Anti Tg) \%20 pozitif, anti tiroid peroksidazı (Anti TPO) \%5 pozitif, Omori ve ark. (20) Anti Tg'yi \%67 pozitif, Qari ve ark. (21) Anti Tg'yi \%80 pozitif olarak bildirmişlerdir. Bizim çalışmamızda ise, hasta grubunda Anti $\mathrm{Tg} 43$ hastanın 20'sinde (\%46.5) pozitif, Anti TPO'ı 36 hastanın 2'sinde (\%5.6) pozitifti. Bu veriler doğrultusunda, tiroid antikorları pozitif olan tirotoksik hastalarda otoimmün tiroid hastalığı düşünülüp subakut tirodit ekarte edilmemelidir. Görüldüğü gibi vakalarımızın neredeyse yarısında otoantikor pozitif subakut tiroidit mevcut. 


\section{Sonuç}

Özellikle bahar aylarında boğaz ağrısı ve sedimantasyon yüksekliği olan hastalarda subakut tiroidit ayırıcı tanıda düşünülüp tiroid fonksiyon testleri istenmelidir.

Subakut tiroiditli hastalarda Anti $\mathrm{Tg}$ düzeylerinin yüksek olabileceği gözlenmiş olup, Anti Tg pozitif hastalarda subakut tiroidit tanısı dışlanmamalıdır. Otoimmün tiroid hastalıkları ile subakut tiroidit ayırıcı tanısında Anti Tg'den ziyade Anti TPO negatifliğinin daha değerli olduğu söylenebilir.

Subakut tiroiditli hastalarda T4/T3 oranı ve nötrofil lenfosit oranının artmış olduğu ve MPV düzeyininde düşük olduğu söylenebilir. Özellikle azalmış MPV düzeyinin subakut tiroidit vakalarının diğer hipertiroidi tiplerinden ayrımında yardımcı bir parametre olarak kullanılmasına olanak sağlayabilir. Bu konuda ileri çalışmalara intiyaç vardır.

\section{Kaynaklar}

1. Wondisford FE, Radovick S. Clinical Management of Thyroid Disease. 1st Edition. Philadelphia: Saunders; 2009: 191-202.

2. Desailloud R, Hober D. Viruses and thyroiditis: an update. Virol J 2009; 6: 5.

3. Papadakis MA, McPhee SJ. Current Medical Diagnosis \& Treatment. 54th Edition. Publisher: McGraw-Hill Education / Medical; 2015: 1110.

4. Pearce EN, Bogazzi F, Martino $E$ et al. The prevalence of elevated serum Creactive protein levels in inflammatory and noninflammatory thyroid disease. Thyroid 2003; 13 (7): 643-8.

5. İliçin G, Biberoğlu K, Süleymanlar G, Ünal S. İç hastalıkları. 3. Baskı. Ankara: Ayrıntı Basımevi; 2012: $1967-2023$.

6. Sato J, Uchida T, Komiya K, et al. Comparison of the therapeutic effects of prednisolone and nonsteroidal antiinflammatory drugs in patients with subacute thyroiditis. Endocrine 2017; 55 (1): 209-14.

7. Fatourechi V, Aniszewski JP, Fatourechi GZ, Atkinson EJ, Jacobsen SJ. Clinical features and outcome of subacute thyroiditis in an incidence cohort: Olmsted County, Minnesota, study. J Clin Endocrinol Metab 2003; 88 (5): 2100-5.

8. Erdem N, Erdogan M, Ozbek M, et al. Demographic and clinical features of patients with subacute thyroiditis: results of 169 patients from a single university center in Turkey. J Endocrinol Invest 2007; 30 (7): $546-50$.

9. Alfadda AA, Sallam RM, Elawad GE, AIDhukair H, Alyahya MM. Subacute Thyroiditis: Clinical Presentation and Long Term Outcome. Int J Endocrinol 2014; 2014: 794943.

10. Cappelli C, Pirola I, Gandossi E, Formenti AM, Agosti B, Castellano M. Ultrasound findings of subacute thyroiditis: a single institution retrospective review. Acta Radiologica 2014; 55 (4): 429-33.

11. Martino E, Buratti $L$ et al. High prevalence of subacute thyroiditis during summer season Italy. J Endocrinol Invest $1987 ; 10(3): 321-3$.

12. Uysal AR, Çorapçıoğlu D, Çetinarslan B, ve ark. Subakut tiroiditli 28 olgunun klinik laboratuvar değerlendirmesi. Ankara Tıp Mecmuası (The journal of the faculty of medicine) 1995; 48: 469-74.

13. Schmoeller D, Picarelli MM, Munhoz TP, Poli de Figueiredo CE, Staub HL. Mean Platelet Volume and Immature Platelet Fraction in Autoimmune Disorders. Front Med (Lausanne) 2017; 4: 146.

14. Kaushansky K. Historical review: megakaryopoiesis and thrombopoiesis. Blood 2008; 111 (3): $981-6$

15. Ford HC, Toomath RJ, Carter JM, Delahunt JW, Fagerstrom JN. Mean platelet volume is increased in hyperthyroidism. Am J Hematol 1988; 27 (3): 190-3.

16. Lippi G, Danese E, Montagnana M, Nouvenne A, Meschi T, Borghi L. Mean platelet volume is significantly associated with serum levels of thyroid-stimulating hormone in a cohort of older euthyroid subjects. Endocrine Res 2015; 40 (4): 227-30.

17. Ren X, Meng Z, Liu M, et al. No associations exist between mean platelet volume or platelet distribution width and thyroid function in Chinese. Medicine 2016; 95 (40): e4573.

18. Mortoglou A, Candiloros H. The serum triiodothyronine to thyroxine (T3/T4) ratio in various thyroid disorders and after Levothyroxine replacement therapy. Hormones 2004; 3 (2): 120-6.

19. Ross DS, Burch HB, Cooper DS, et al. American Thyroid Association Guidelines for Diagnosis and Manangement of Hyperthyroidism and Other Causes of Thyrotoxicosis. Thyroid 2016; 26 (10): $1343-421$.

20. Omori N, Omori K, Takano K. Association of the Ultrasonographic Findings of Subacute Thyroiditis with Thyroid Pain and Laboratory Findings. Endocr J 2008; 55 (3): 583-8.

21. Qari FA, Maimani AA. Subacute thyroiditis in Western Saudi Arabia. Saudi Med J 2005; 26 (4): 630-3. 